J. Lake Sci.(湖泊科学), 2021, 33(1): 204-217

DOI 10. 18307/2021. 0111

(c) 2021 by Journal of Lake Sciences

\title{
河流大型底栖动物对环境压力的响应: 以太湖、巢湖流域为例
}

\author{
张 又 $^{1}$, 蔡永久 ${ }^{1}$, 张 颖 $^{2}$, 高俊峰 ${ }^{1}$, 李宽意 ${ }^{1,3 * *}$ \\ (1: 中国科学院南京地理与湖泊研究所,湖泊与环境国家重点实验室,南京 210008) \\ $(2:$ 江苏省水利工程规划办公室,南京 210029) \\ (3: 中国科学院大学中丹学院, 北京 100049)
}

\begin{abstract}
摘 要: 为了解河流大型底栖动物对环境压力的响应关系, 以人类干扰程度不同的太湖流域和巢湖流域为研究区, 系统 调查区域内河流大型底栖动物, 结合水体、沉积物理化数据及生境质量状况, 运用空间分析和多元统计分析等方法, 探讨 了大型底栖动物多样性及典型物种对关键环境因素的响应规律. 结果表明, 太湖流域和巢湖流域的环境质量和大型底栖 动物群落结构均差异较大, 巢湖流域的生境质量优于太湖流域, 巢湖流域平原区部分点位的水体营养盐 (特别是氮浓度) 高于太湖流域平原区. 巢湖流域丘陵区的敏感型物种 (主要为水生昆虫) 密度远高于太湖流域丘陵区, 太湖流域丘陵区的 耐污型物种(晹毛纲)平均密度稍高于巢湖流域丘陵区, 而巢湖流域平原区的塞毛纲霍甫水丝蚂 (Limnodrilus hoffmeisteri) 和苏氏尾鳃蚂 (Branchiura sowerbyi) 平均密度远高于太湖流域平原区. 广义加性模型建立的响应关系曲线表明, 栖境多样 性和总氮浓度可以作为生物多样性的指示因子. 铜锈环棱螺 (Bellamya aeruginosa)、椭圆萝卜螺 (Radix swinhoei)、河蚬 (Corbicula fluminea) 、霍甫水丝蚂、苏氏尾鳃蚓、黄色羽摇蚊 (Chironomus flaviplumus) 等特征物种与特定环境因子的响应关 系显著, 这些物种也可以作为环境监测的指示物种. 底栖动物一环境梯度的响应曲线能够定量地描述底栖动物群落对环 境因子的响应关系, 有利于深人了解水体水质、营养状态及生境质量与大型底栖动物群落结构的相关关系, 进而预测不 同人为干扰下大型底栖动物群落结构的变化趋势和演替过程.
\end{abstract}

关键词: 太湖流域;巢湖流域; 大型底栖动物;响应曲线;广义加性模型

\section{The response of benthic macroinvertebrate communities to environmental pressures in} streams and rivers: A case study of Taihu and Chaohu Basins*

Zhang You ${ }^{1}$, Cai Yongjiu ${ }^{1}$, Zhang Ying ${ }^{2}$, Gao Junfeng ${ }^{1} \&$ Li Kuanyi $^{1,3 * *}$

(1: State Key Laboratory of Lake Science and Environment, Nanjing Institute of Geography and Limnology, Chinese Academy of Sciences, Nanjing 210008, P.R. China)

(2: Water Resources Planning Bureau of Jiangsu Province, Nanjing 210029, P.R.China)

(3: Sino-Danish College, University of Chinese Academy of Sciences, Beijing 100049, P.R.China)

\begin{abstract}
This study seeks to clarify the response of benthic macroinvertebrate communities to environmental pressures in streams and rivers, and two regions with different degrees of human disturbance, i.e. Taihu Basin and Chaohu Basin, were chosen as the study area. Benthic macroinvertebrate communities in these two regions were investigated, as well as the physicochemical conditions of the water and sediment and habitat condition. Spatial analysis and multivariate statistical analysis were used to explore how macroinvertebrates respond to the environmental variables. The results showed that the environmental quality and the benthic macroinvertebrate communities were significantly different in these two basins, indicating that different disturbance intensities had different effects on the ecological environment and benthic macroinvertebrates. The habitat quality of Chaohu Basin was better than that of Taihu Basin. Besides, nutritional concentrations in the plain area of Chaohu Basin, especially the nitrogen concentration were high-

* 2020-05-12 收稿; 2020-06-20 收修改稿.

国家自然科学基金项目 (31930074,32001156,31670466)、中国科学院科技服务网络计划区域重点项目 (KFJ-STSQYZD-156)、江苏省水利科技项目 (2018003) 和中国科学院南京地理与湖泊研究所引进人才启动项目 (NIGLAS2019QD02) 联合资助.

** 通信作者;E-mail: kyli@ niglas.ac.cn.
\end{abstract}


er than that in the plain area of Taihu Basin. The hilly area of Chaohu Basin has more sensitive species (e.g. aquatic insects) and less pollution-tolerant species (e.g. oligochaetes) than Taihu Basin, and the plain area of Chaohu Basin has much higher abundance of oligochaetes (mainly Limnodrilus hoffmeisteri and Branchiura sowerbyi) than Taihu Basin. Based on generalized additive model, response curves showed that habitat diversity and total nitrogen can be used as indicators for taxa richness and biodiversity. Characteristic species, such as Bellamya aeruginosa, Radix swinhoei, Corbicula fluminea, L. hoffmeisteri, B. sowerbyi, Chironomus flaviplumus, could be used as environmental monitoring indicators due to their response to specific environmental factors. The response curves can reveal the relationship between benthic macroinvertebrate communities and water quality, nutritional status and habitat quality, which can be used to predict benthic macroinvertebrate communities and succession process under different human disturbances.

Keywords: Taihu Basin; Chaohu Basin; benthic macroinvertebrate; response curves; generalized additive models

大型底栖动物是淡水生态系统的一个重要生物类群, 是物质循环和能量流动的主要环节, 有着承上启 下的关键作用. 底栖动物可以促进有机碎屑分解, 调节泥一水界面的物质交换, 维持生物完整性等, 在淡水生 态系统中发挥着重要的作用 ${ }^{[1-2]}$. 底栖动物具有相对较长的生命周期、活动范围小, 能够综合反映较长时间 段内的环境质量 ${ }^{[3]}$; 不同物种对环境变化的敏感程度不同, 如蜉蝣目物种对水体污染较为敏感, 而塞毛类则 为中污染和重污染的指示物种 ${ }^{[4-5]}$; 当水体受到污染时, 底栖动物群落结构也随之发生变化, 底栖动物的群 落结构、优势种类和密度等生物指标可以反映不同类型环境压力的影响 ${ }^{[6]}$. 因此, 底栖动物常被用于生物监 测和水质评价 ${ }^{[7-8]}$.

“生态区” 的概念由 Crowly 于 1967 年首次提出 ${ }^{[9]}$. 生态区是指在地理空间上具有独特的自然群落、物种 和环境条件组合特征, 同时具有相对一致的水生态系统组成、结构、格局、过程和功能的水体或具有 “水陆一 致性” 的陆水联合体 ${ }^{[10-11]}$. “十一五” 以来, 我国系统地开展了流域水生态功能分区理论与方法研究, 建立水 生态功能分区指标体系, 建立全国水生态功能分区技术框架 ${ }^{[12]}$, 主要以流域为单元根据环境要素、水生态系 统特征及生态服务功能在不同地域的差异性和相似性开展了水生态功能区划分工作 ${ }^{[13]}$. 流域水生态功能 分区不仅反映了水生态空间分布格局的差异, 也在一定程度上考虑了人类活动对水生态系统的影响, 实现 了自然要素与功能要素的结合, 提出了面向水生态保护的管理区域, 推动了从水环境管理向水生态管理理 念的转变 ${ }^{[14]}$. 生态区自然环境特征 (如海拔、水文特征等) 的变化, 是决定区域内生物群落特征的关键因素. 因此, 以生态区为空间单元来研究河流底栖动物群落结构的分布特征, 可以有效协助淡水生态系统的管理 工作 ${ }^{[15-16]}$. 欧盟在生态区的基础上建立了以水生生物指标为核心的生态质量评价方法, 通过 “压力一状态一 响应” 关系分析, 判断水体受损状况, 分别针对受损水体和未受损水体明确保护目标 ${ }^{[17]}$. 我国以生态区为空 间单元来分析底栖动物群落的研究较少. 孟云飞等 ${ }^{[18]}$ 以水生态功能区为单元研究了浑太河流域大型底栖 动物群落特征, 发现不同水生态功能区影响大型底栖动物群落结构的环境因子存在差异性. 张又等 ${ }^{\left[{ }^{[19]}\right.}$ 对太 湖流域的研究发现, 西部丘陵区和东部平原区的底栖动物优势种差异明显, 且两个生态区受污染程度差异 较大.

中国经济与社会的发展迅速, 正处于全面建成小康社会决胜阶段, 农业稳定增长, 农业现代化深人发 展,工业化水平进一步提高, 经济的地域性差异, 给不同地区的生态环境造成了不同类型和不同程度的影响. 对于不同的地域, 工农业发展的侧重和发展程度的差异都在很大程度上决定了人为干扰对该地区环境的影 响方式和程度. 太湖流域和巢湖流域是较早完成水生态功能区划分的流域 ${ }^{[20-21]}$, 且两个流域的土地利用类 型差异较大, 分别以工业发展和农业发展为主, 水生态系统造成的环境压力不同. 因此, 本研究以太湖流域 和巢湖流域为研究区, 对比分析两流域丘陵区和平原区的水环境与栖息地质量差异、底栖动物群落差异及 其主要驱动因素; 综合考虑两个流域的理化环境和底栖动物群落组成, 分析底栖动物特征种对关键环境胁 迫因子的响应关系, 以期为流域水生态保护目标的确定提供科学依据.

\section{1 材料与方法}

\section{1 研究区域与采样点布设}

太湖流域 ( $30^{\circ} 7^{\prime} 19^{\prime \prime} \sim 32^{\circ} 14^{\prime} 56^{\prime \prime} \mathrm{N}, 119^{\circ} 3^{\prime} 1^{\prime \prime} \sim 121^{\circ} 54^{\prime} 26^{\prime \prime} \mathrm{E}$ ) 位于长江三角洲地区, 北抵长江, 东临东海, 南 
滨钱塘江, 西以天目山、茅山为界, 面积 $3.69 \times 10^{4} \mathrm{~km}^{2}$, 地势中部低洼, 总体呈现西部高东部低的趋势. 流域内 大小湖泊星罗棋布, 以太湖为中心, 河流与湖泊相互交错, 呈水网状. 流域河道总长 12 万 $\mathrm{km}$, 河网密度达 $3.25 \mathrm{~km} / \mathrm{km}^{2}$, 是我国河网密度最大的地区 ${ }^{[19,22]}$.

巢湖流域 $\left(31^{\circ} 25^{\prime} 28^{\prime \prime} \sim 31^{\circ} 43^{\prime} 28^{\prime \prime} \mathrm{N}, 117^{\circ} 16^{\prime} 54^{\prime \prime} \sim 117^{\circ} 51^{\prime} 46^{\prime \prime} \mathrm{E}\right)$ 属长江水系, 流域面积约 $1.3 \times 10^{4} \mathrm{~km}^{2}$. 巢 湖流域地势的总轮廓是东西向较长, 地形总体北高南低, 西高东低, 中间低洼平坦. 西南为山区, 东北为丘陵 及浅山区, 东南及沿湖为平原. 流域内河网密布、纵横交错, 主要支流发源于大别山区, 共 33 条出人湖河流, 呈放射状直接或间接汇人巢湖 ${ }^{[23]}$.

本研究在太湖流域和巢湖流域分别布设 93 和 147 个采样点, 其中太湖流域西部丘陵区 (E1) 和东部平 原区 (E2) 布设了 22 和 71 个采样点, 巢湖流域西部丘陵区 (e1) 和东部平原区 $(\mathrm{e} 2)$ 分别布设了 47 和 100 个 采样点,涵盖了生态区内的主要溪流和河流 (图 1).
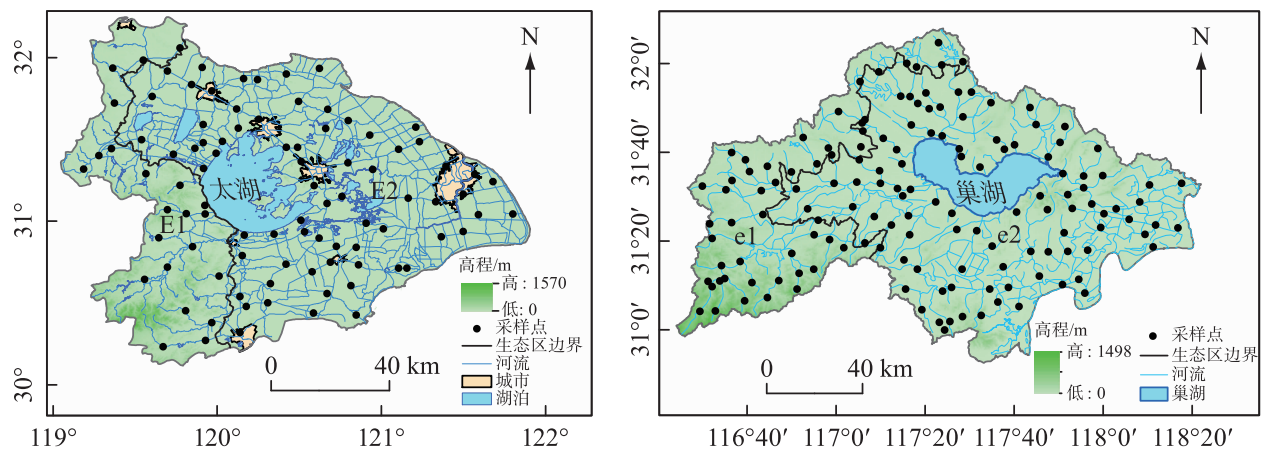

图 1 太湖流域和巢湖流域采样点分布

Fig.1 Sampling sites of Taihu Basin and Chaohu Basin

\section{2 底栖动物样品采集和鉴定}

太湖流域底栖动物样品采集时间为 2012 年 10 月,巢湖流域底栖动物样品采集时间为 2013 年 4 月. 大 型底栖动物样品采用 $\mathrm{D}$ 型抄网或彼得逊采泥器采集. 对于可以涉水的溪流及小型河流, 采用 $\mathrm{D}$ 形抄网进行 底栖动物样品采集, 每个采样点采集 10 个样方, 包含 $100 \mathrm{~m}$ 河段内的主要生境, 每个样方的大小为 $30 \mathrm{~cm} \times$ $50 \mathrm{~cm}$. 每个样点的 10 个样方混合成一个样品. 对于无法涉水的大型河流, 采用 $1 / 16 \mathrm{~m}^{2}$ 的彼得逊采泥器进 行底栖动物样品采集, 每个样点采集 6 次, 并混合成一个样品. 每个样点所采集的样品, 需经过 60 目尼龙篮 网进行现场笁洗, 剩余物带回实验室, 置于白色瓷盘中, 将所有底栖动物逐一挑出, 并用 $7 \%$ 福尔马林溶液固 定保存.

底栖动物的鉴定需在解剖镜和显微镜下进行, 所有样品都鉴定至尽可能低的分类单元 ${ }^{[24-27]}$. 每个采样 点所采到的底栖动物按不同种类准确地统计数量并用电子天平称重, 称重前需用滤纸吸去表面固定液. 软 体动物带壳称重. 根据每个样点的采样面积换算出每个样点的每种底栖动物的密度 $\left(\mathrm{ind} / \mathrm{m}^{2}\right)$ 和生物量 $\left(\mathrm{g} / \mathrm{m}^{2}\right)$.

\section{3 水环境与栖息地调查}

针对每一个样点, 现场采用多参数水质监测仪 (YSI $6600 \mathrm{~V} 2$ ) 测定表层 (30 50 cm 深度) $\mathrm{pH}$ 值、电导率 (Conductivity)、溶解氧 (DO)、盐度 (Salinity) 和浊度 (Turbidity), 同时采集水面以下 $0.5 \mathrm{~m}$ 深度的水样. 若水 深不足 $0.5 \mathrm{~m}$ 时, 则选择中间深度处. 采集的水样冷冻保存并带回实验室分析. 氨氮 $\left(\mathrm{NH}_{3}-\mathrm{N}\right)$ 、硝态氮 $\left(\mathrm{NO}_{3}^{-}-\mathrm{N}\right)$ 、正磷酸盐 $\left(\mathrm{PO}_{4}^{3-}-\mathrm{P}\right)$ 浓度采用微量流动注射仪测定, 总悬浮颗粒物( TSS )、叶绿素 $a(\mathrm{Chl} . a)$ 、总氮 $(\mathrm{TP})$ 、总磷 $(\mathrm{TP})$ 、高锰酸盐指数 $\left(\mathrm{COD}_{\mathrm{Mn}}\right)$ 以及溶解性总有机碳 $(\mathrm{DOC})$ 浓度的测定方法参考《水和废水监测 分析方法》 ${ }^{[28]}$.

通过现场调查, 根据质量状况优劣程度, 将栖境多样性 ( Habitat)、河道变化 (Channel)、交通干扰程度 (Transportation)、河岸带土地利用 (Land)、底质异质性 (Substrate) 5 个反映生境质量的参数分为: 好 (16 
20)、较好 $(11 \sim 15) 、 一$ 般 $(6 \sim 10)$ 和差 $(0 \sim 5) 4$ 个等级 ${ }^{[19,29-30]}$, 具体的打分标准见表 1 .

表 1 生境质量评价指标及标准

Tab.1 Indicators' criteria of river habitat conditions

\begin{tabular}{|c|c|c|c|c|}
\hline 评价指标 & 好 & 较好 & 一般 & 差 \\
\hline 栖境多样性 & $\begin{array}{l}\text { 有水生植被、枯枝落 } \\
\text { 叶、倒木、倒凹堤岸和 } \\
\text { 巨石等各种小栖境 }\end{array}$ & $\begin{array}{l}\text { 有水生植被、枯枝落叶 } \\
\text { 和倒凹堤岸等小栖境 }\end{array}$ & $\begin{array}{l}\text { 以 } 1 \text { 种或 } 2 \text { 种小栖境 } \\
\text { 为主 }\end{array}$ & $\begin{array}{l}\text { 以 } 1 \text { 种小栖境为主, 底质 } \\
\text { 多以淤泥或细沙为主 }\end{array}$ \\
\hline 河道变化 & $\begin{array}{l}\text { 渠道化没有出现或很 } \\
\text { 少出现,河道维持正常 } \\
\text { 模式 }\end{array}$ & $\begin{array}{l}\text { 渠道化出现较少,通常 } \\
\text { 在桥墩周围处出现渠 } \\
\text { 道化,对水生生物影响 } \\
\text { 较小 }\end{array}$ & $\begin{array}{l}\text { 渠道化比较广泛,在两 } \\
\text { 岸有筑堤或桥梁支柱 } \\
\text { 出现,对水生生物有一 } \\
\text { 定影响 }\end{array}$ & $\begin{array}{l}\text { 河岸由铁丝和水泥固定, } \\
\text { 对水生生物的影响很严 } \\
\text { 重, 使其生活环境完全 } \\
\text { 改变 }\end{array}$ \\
\hline $\begin{array}{c}\text { 交通干扰 } \\
\text { 程度 }\end{array}$ & $\begin{array}{l}\text { 无人为干扰或少有人 } \\
\text { 为干扰 }\end{array}$ & $\begin{array}{l}\text { 人为干扰较小,有少量 } \\
\text { 的非机动车通过 }\end{array}$ & $\begin{array}{l}\text { 人为干扰较大, 并有少 } \\
\text { 量的船只或机动车 } \\
\text { 通过 }\end{array}$ & $\begin{array}{l}\text { 人为干扰很大, 交通要道 } \\
\text { 必经之路, 经常有船只或 } \\
\text { 机动车通过 }\end{array}$ \\
\hline $\begin{array}{l}\text { 河岸带 } \\
\text { 土地利用 }\end{array}$ & $\begin{array}{l}\text { 河岸两侧为无耕作土 } \\
\text { 壤, 营养丰富 }\end{array}$ & $\begin{array}{l}\text { 河岸一侧为无耕作土 } \\
\text { 壤,另一侧为耕作土壤 }\end{array}$ & $\begin{array}{l}\text { 河岸两侧为耕作土壤, } \\
\text { 需要施加化肥和农药 }\end{array}$ & $\begin{array}{l}\text { 河岸两侧为耕作废弃的裸 } \\
\text { 露的风化土壤层, 营养物 } \\
\text { 质很少 }\end{array}$ \\
\hline $\begin{array}{c}\text { 底质异 } \\
\text { 质性 }\end{array}$ & $\begin{array}{l}\text { 超过 } 75 \% \text { 的石块、砾石 } \\
\text { 或卵石,其它为淤泥 }\end{array}$ & $\begin{array}{l}50 \% \sim 75 \% \text { 的石块、砾 } \\
\text { 石或卵石, 其他为淤泥 }\end{array}$ & $\begin{array}{l}25 \% \sim 50 \% \text { 的石块、砾 } \\
\text { 石或卵石, 其他为淤泥 }\end{array}$ & $\begin{array}{l}\text { 不足 } 25 \% \text { 的石块、砾石或 } \\
\text { 卵石, 其他为淤泥 }\end{array}$ \\
\hline 分值 & $16 \sim 20$ & $11 \sim 15$ & $6 \sim 10$ & $0 \sim 5$ \\
\hline
\end{tabular}

\section{4 数据分析处理}

采用主成分分析 (PCA) 分别对两个流域的丘陵区和平原区的环境因子排序, 从而提取出能够尽可能多 地反映原来变量信息的综合变量, 寻找研究区环境梯度. 采用相似性分析 (analysis of similarities, ANOSIM) 检验两个流域丘陵区和平原区的底栖动物群落组成的差异显著性, 并利用相似百分比分析 ( similarity percentage,SIMPER) 找出对两流域丘陵区和平原区底栖动物群落差异贡献最大的种类及其对差异的贡献

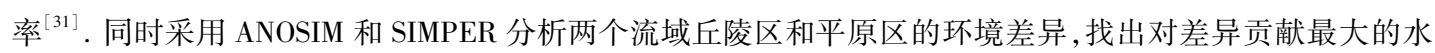
环境与栖息地指标,及其对差异的贡献率.

采用典范对应分析 (canonical correspondence analysis, CCA) 分别分析两流域丘陵区和平原区的底栖动 物群落与环境因子之间的关系, 用 CCA 排序图将物种、样点和环境因子绘出, 直观地呈现出种类组成及群落 分布与环境因子之间的关系 ${ }^{[32]}$. 分析时, 物种数据进行平方根转换, 环境因子进行 $\lg (x+1)$ 转换 $(\mathrm{pH}$ 值除 外). 环境因子的篮选采用向前引人法, 保留能通过蒙特卡罗置换检验的显著因子 $(P<0.1)$.

广义加性模型 (generalized additive models, GAM) 是适用于响应变量与解释变量呈非线性关系的分析方 法 ${ }^{[33]}$. GAM 模型对数据的分布限制较少, 可以是高斯分布、二项式分布、泊松分布及其他复杂的分布等, 尤 其适用于某些离散数据, 因此 GAM 模型可以较好地分析因变量与多自变量之间的非线性关系 ${ }^{[34]}$. 因 CCA 只能总体确定影响底栖动物群落结构的环境因子, 但不同物种对环境因子的响应模式是不同的, 为明确特 征种和多样性对环境因子的响应关系, 本研究采用 GAM 模型, 以泊松分布类型及 AIC (Akaike information criterion) 最小为最优的原则篮选并拟合底栖动物特征种与环境因素的响应关系, 确定底栖动物特征种响应 关系显著 $(P<0.05)$ 的环境因子, 定量地解析底栖动物对环境压力的响应模式.

本研究的 PCA、CCA 和 GAM 分析在 CANOCO 4.5 软件中完成, ANOSIM 和 SIMPER 分析在 PRIMER 5.0 软件中完成.

\section{2 结果与分析}

\section{1 水环境与栖息地质量}

两个流域丘陵区环境因子的主成分分析排序图 (图 2) 显示, 第 1 主成分 (PC1) 与 Chl. $a$ 、Conductivity、Sa- 
linity、 $\mathrm{PO}_{4}^{3-}-\mathrm{P} 、 \mathrm{CaCO}_{3}$ 、Turbidity 呈正相关, 与底质异质性、交通干扰程度、河道变化、河岸带土地利用、栖境多 样性、DO 呈负相关; 第 2 主成分 (PC2) 与 $\mathrm{NH}_{3}-\mathrm{N} 、 \mathrm{COD}_{\mathrm{Mn}}$ 呈负相关. 前两个主成分的方差解释率分别为 $53.2 \%$ 和 $17.8 \%$. 从排序图可以看出巢湖流域丘陵区的栖息地质量优于太湖流域丘陵区, 而太湖流域丘陵区的水 体营养盐浓度高于巢湖流域丘陵区. 平原区环境因子的主成分分析排序图 (图 2) 显示, 第 1 主成分 (PC1) 与 Conductivity、Turbidity、 $\mathrm{PO}_{4}^{3-}-\mathrm{P} 、 \mathrm{NO}_{3}^{-}-\mathrm{N}$ 呈显著正相关, 与栖境多样性、河道变化、河岸带土地利用、交通干扰 程度、DO 呈显著正相关. 第 2 主成分 $(\mathrm{PC} 2)$ 与 $\mathrm{TP} 、 \mathrm{NH}_{3}-\mathrm{N} 、 \mathrm{Chl} . a 、 \mathrm{TN} 、 \mathrm{COD}_{\mathrm{Mn}}$ 呈显著正相关, 与 Substrate 呈显 著负相关. 前两个主成分的方差解释率分别为 $54.8 \%$ 和 $17.6 \%$. 类似于丘陵区, 巢湖流域平原区的栖息地质 量要优于太湖流域平原区, 但巢湖流域平原区仍有部分样点营养盐浓度较高. 综合丘陵区和平原区的主成 分分析排序图可以看出, 反映生境质量的指标(栖境多样性、河道变化、河岸带土地利用、交通干扰程度和底 质指数) 与 $\mathrm{DO}$ 和 $\mathrm{pH}$ 呈负相关关系, 而与营养盐等水质参数均呈负相关关系.
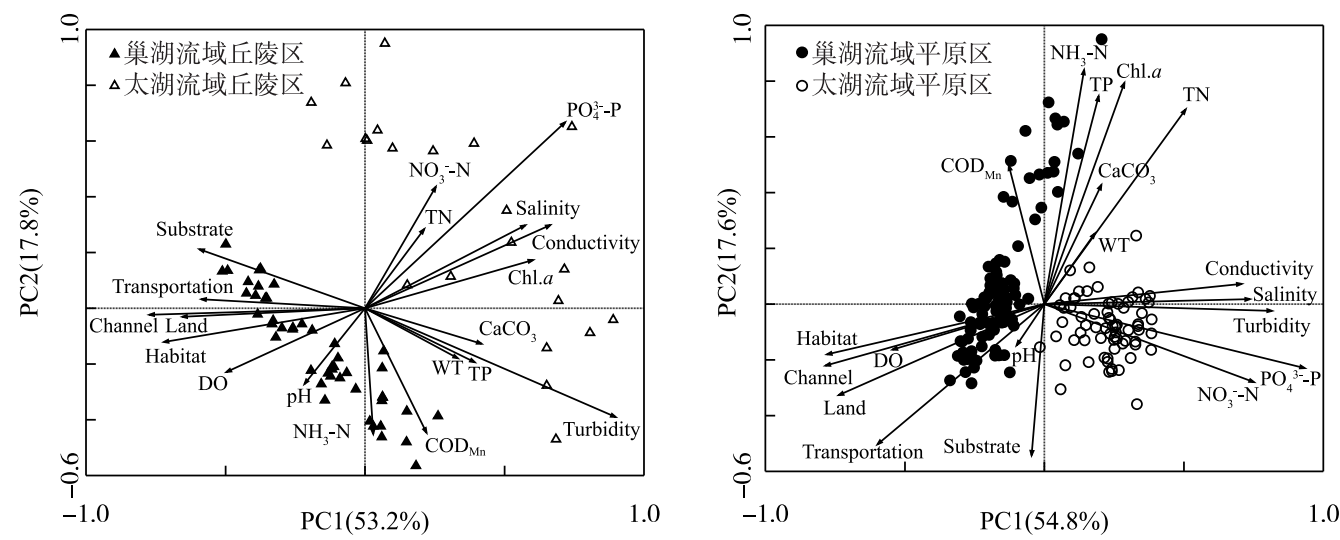

图 2 水环境与栖息地质量的主成分分析排序图

Fig.2 Principal component analysis of water quality and habitat quality factors

One-way ANOSIM 结果显示, 巢湖流域丘陵区与太湖流域丘陵区的环境特征差异显著 $(P<0.01, R=$ $0.402)$, 巢湖流域平原区与太湖流域平原区的环境特征差异显著 $(P<0.01, R=0.528)$. SIMPER 分析结果显 示浊度和 Chl. $a$ 是造成两个流域环境特征差异的主要理化因素 (表 2 , 表 3 ), 两个丘陵区的主要差异还包括 底质组成、水体 DO、河道变化和栖境多样性,而两个平原区的主要差异还包括栖境多样性、河道变化、TN、 $\mathrm{NO}_{3}^{-}-\mathrm{N}$ 和河岸带土地利用. 太湖流域丘陵区的浊度和 Chl. $a$ 均远高于巢湖流域的丘陵区和平原区, 但巢湖流 域平原区水体 TN 浓度明显高于太湖流域平原区. 整体上看, 巢湖流域和太湖流域的环境质量差异较大. 巢 湖流域丘陵区和平原区的生境质量均优于太湖流域, 但巢湖流域平原区部分点位的水体营养盐浓度高于太 湖流域平原区.

表 2 两个流域丘陵区的环境特征差异的主要因子及其均值 ${ }^{*}$

Tab.2 The main environmental factors and their mean values of the hilly areas in the two basins

\begin{tabular}{cccc}
\hline 主要因子 & 贡献率 $/ \%$ & 太湖流域丘陵区 & 巢湖流域丘陵区 \\
\hline 浊度 $/ \mathrm{NTU}$ & 23.41 & 23.25 & 10.47 \\
叶绿素 $a /(\mu \mathrm{g} / \mathrm{L})$ & 13.69 & 6.30 & 3.73 \\
底质异质性 & 8.00 & 3.57 & 9.36 \\
溶解氧 $/(\mathrm{mg} / \mathrm{L})$ & 5.70 & 7.03 & 11.26 \\
河道变化 & 5.62 & 10.00 & 14.06 \\
栖境多样性 & 5.35 & 10.00 & 13.96 \\
\hline
\end{tabular}

*差异贡献率累计至 60\%. 
表 3 两个流域平原区的环境特征差异的主要因子及其均值“

Tab.3 The main environmental factors and their mean values of the plain areas in the two basins

\begin{tabular}{cccc}
\hline 主要因子 & 贡献率/\% & 太湖流域平原区 & 巢湖流域平原区 \\
\hline 浊度 $/ \mathrm{NTU}$ & 17.49 & 70.20 & 18.43 \\
叶绿素 $a /(\mu \mathrm{g} / \mathrm{L})$ & 8.72 & 7.40 & 18.77 \\
栖境多样性 & 8.71 & 3.00 & 10.96 \\
河道变化 & 8.05 & 3.00 & 10.58 \\
总氮 $/(\mathrm{mg} / \mathrm{L})$ & 6.77 & 3.74 & 4.51 \\
硝态氮 $/(\mathrm{mg} / \mathrm{L})$ & 6.32 & 1.48 & 0.21 \\
河岸带土地利用 & 6.21 & 4.00 & 8.94 \\
\hline
\end{tabular}

*差异贡献率累计至 $60 \%$.

\section{2 大型底栖动物群落结构}

One-way ANOSIM 结果显示, 巢湖流域丘陵区与太湖流域丘陵区的底栖动物群落结构差异显著 $(P<$ $0.01, R=0.133)$, 巢湖流域平原区与太湖流域平原区的底栖动物群落结构差异显著 $(P<0.01, R=0.724)$.

两个丘陵区底栖动物群落结构的差异物种主要为腹足纲 (8 种)、水生昆虫 (5 种)、软甲纲 (3 种)、双壳 纲 (3 种)、寡毛纲 (2 种) 及摇蚊幼虫 (3 种) (表 4). 从平均密度来看, 巢湖流域丘陵区的水生昆虫密度远高

表 4 两个流域丘陵区底栖动物群落差异的主要物种对组间差异的贡献率及其密度均值*

Tab.4 Characteristic species, their contributions to between-group dissimilarity, and their mean abundance in the hilly areas of the two basins

\begin{tabular}{|c|c|c|c|}
\hline \multirow{2}{*}{ 物种 } & \multirow{2}{*}{ 贡献率/\% } & \multicolumn{2}{|c|}{ 平均密度 $/\left(\right.$ ind. $\left./ \mathrm{m}^{2}\right)$} \\
\hline & & 太湖流域丘陵区 & 巢湖流域丘陵区 \\
\hline 铜锈环棱螺 Bellamya aeruginosa & 8.02 & 44.16 & 42.61 \\
\hline 扁蜉属 1 种 Heptagenia $\mathrm{sp.}$ & 5.34 & 4.71 & 24.32 \\
\hline 锯齿新米虾 Neocaridina denticulata & 4.76 & 14.44 & 3.31 \\
\hline 椭圆萝卜螺 Radix swinhoei & 4.76 & 4.74 & 13.40 \\
\hline 膀胱螺属 1 种 Physa sp. & 4.75 & 6.18 & 9.38 \\
\hline 方格短沟蜷 Semisulcospira cancelata & 4.59 & 9.06 & 15.24 \\
\hline 河蚬 Corbicula fluminea & 3.99 & 8.58 & 5.88 \\
\hline 大沼螺 Parafossarulus eximius & 2.92 & 3.25 & 2.55 \\
\hline 短脉纹石蛾属 1 种 Cheumatopsyche sp. & 2.90 & 0 & 5.82 \\
\hline 霍甫水丝蚓 Limnodrilus hoffmeisteri & 2.90 & 2.28 & 1.96 \\
\hline 纹沼螺 Parafossarulus striatulus & 2.75 & 2.11 & 5.11 \\
\hline 长角涵螺 Alocinma longicornis & 2.51 & 1.80 & 12.37 \\
\hline 苏氏尾鳃蚓 Branchiura sowerbyi & 2.26 & 1.98 & 1.33 \\
\hline 纹石蛾属 1 种 Hydropsyche sp. & 2.18 & 0.04 & 4.93 \\
\hline 秀丽白虾 Exopalaemon modestus & 2.12 & 1.66 & 0.24 \\
\hline 梯形多足摇蚊 Ploypedilum scalaenum & 1.93 & 3.04 & 0.64 \\
\hline 淡水壳菜 Limnoperna fortunei & 1.80 & 3.17 & 0.98 \\
\hline 四节蜉属 1 种 Baetis sp. & 1.79 & 0.23 & 2.50 \\
\hline 林间环足摇蚊 Cricotopus sylvestris & 1.61 & 0.36 & 1.67 \\
\hline 光滑狭口螺 Stenothyra glabra & 1.53 & 1.31 & 0.19 \\
\hline 黄色羽摇蚊 Chironomus flaviplumus & 1.46 & 1.27 & 2.09 \\
\hline 宽基蜉属 1 种 Choroterpes sp. & 1.33 & 0 & 1.71 \\
\hline 圆顶珠蚌 Unio douglasiae & 1.30 & 0.46 & 0.88 \\
\hline 日本沼虾 Macrobrachium nipponense & 1.18 & 0.28 & 1.09 \\
\hline
\end{tabular}

* 差异贡献率累计至 70\%. 
于太湖流域丘陵区, 太湖流域丘陵区的寡毛纲和软甲纲平均密度稍高于巢湖流域丘陵区, 而摇蚊幼虫和双 壳纲在两个流域丘陵区的平均密度相差不大. 虽然铜锈环棱螺在两个流域丘陵区的平均密度接近, 但总体 来讲,巢湖流域丘陵区的腹足纲密度高于太湖流域丘陵区.

两个平原区底栖动物群落结构的差异物种主要为腹足纲 ( 7 种)、软甲纲 ( 2 种)、双壳纲 ( 2 种)、寡毛纲 (2 种) 及摇蚊幼虫 (2 种) (表 5). 从平均密度来看, 巢湖流域平原区的寡毛纲 (霍甫水丝蚓和苏氏尾鳃蚓) 平均密度远高于太湖流域平原区. 腹足纲的铜锈环棱螺、大沼螺、纹沼螺、方格短沟蜷在太湖流域平原区的 平均密度较高, 而长角涵螺、椭圆萝卜螺、尖口圆扁螺在巢湖流域平原区的平均密度较高. 巢湖流域平原区 双壳纲和摇蚊幼虫的平均密度稍高于太湖流域平原区. 而软甲纲在两个流域平原区的平均密度相差不大.

表 5 两个流域平原区底栖动物群落差异的主要物种对组间差异的贡献率及其密度均值 ${ }^{*}$

Tab.5 Characteristic species, their contributions to between-group dissimilarity, and their mean abundance in the plain areas of the two basins

\begin{tabular}{lccc}
\hline \multirow{2}{*}{ 物种 } & & \multicolumn{2}{c}{ 平均密度/(ind./ $\left.\mathrm{m}^{2}\right)$} \\
\hline 霍甫水丝蚓 Limno率/\% & & 太湖流域平原区 & 巢湖流域平原区 \\
铜锈环棱螺 Bellamya aeruginosa & 11.25 & 1309.75 & 2253.59 \\
苏氏尾鳃蚓 Branchiura sowerbyi & 10.87 & 68.78 & 36.44 \\
大沼螺 Parafossarulus eximius & 5.77 & 46.11 & 89.18 \\
黄色羽摇蚊 Chironomus flaviplumus & 5.16 & 9.12 & 2.78 \\
纹沼螺 Parafossarulus striatulus & 4.51 & 0.71 & 35.01 \\
长角涵螺 Alocinma longicornis & 4.43 & 5.61 & 5.05 \\
椭圆萝卜螺 Radix swinhoei & 4.39 & 3.54 & 13.49 \\
锯齿新米虾 Neocaridina denticulata & 3.71 & 0.17 & 3.8 \\
河蚬 Corbicula fluminea & 3.65 & 3.92 & 4.65 \\
秀丽白虾 Exopalaemon modestus & 3.61 & 3.16 & 2.9 \\
方格短沟蜷 Semisulcospira cancelata & 3.33 & 5.46 & 0.04 \\
尖口圆扁螺 Hippeutis cantori & 3.04 & 4.49 & 2.52 \\
林间环足摇蚊 Cricotopus sylvestris & 2.8 & 0.02 & 19.36 \\
淡水壳菜 Limnoperna fortunei & 2.62 & 0.03 & 11.64 \\
\hline
\end{tabular}

*差异贡献率累计至 70\%.

\section{3 底栖动物群落结构的驱动因素}

两个丘陵区除趋势对应分析 (DCA) 结果显示, 第 1 轴的梯度长度为 3.9, 故选用单峰模型 CCA. 向前引 人法最终耖选出 5 个环境因子. 第 1 轴和第 2 轴解释的物种一环境关系变异百分比为 $71.0 \%$. 第 1 轴与底质 异质性 $(R=0.99)$ 、河道变化 $(R=0.81)$ 、交通干扰程度 $(R=0.79)$ 和栖境多样性 $(R=0.67)$ 呈显著正相关, 而 第 2 轴与 $\mathrm{NO}_{3}^{-}-\mathrm{N}$ 呈正相关 $(R=0.68)$ (图 3). 两个丘陵区的采样点在排序图的不同区域相对集中, 表明两个 生态区沿第 1 轴有不同的环境条件. 两个平原区 DCA 分析的第 1 轴梯度长度为 3.1 , 故选用单峰模型 CCA. 向前引人法最终篎选出 9 个环境因子. 第 1 轴和第 2 轴解释的物种一环境关系变异百分比为 $47.6 \%$. 第 1 轴 与栖境多样性 $(R=0.84)$ 、河道变化 $(R=0.83)$ 、交通干扰程度 $(R=0.73)$ 、河岸带土地利用 $(R=0.76)$ 、底质异 质性 $(R=0.72)$ 呈显著正相关, 与 $\mathrm{DO}(R=0.39)$ 呈正相关, 与盐度 $(R=-0.58)$ 呈显著负相关, 与 $\mathrm{NH}_{3}-\mathrm{N}(R=$ -0.31 )、浊度 $(R=-0.36)$ 呈负相关 (图 3). 类似地, 两个平原区的采样点分别在排序图的左右两侧相对集中.

\section{4 大型底栖动物对关键环境因素的响应}

2.4.1 底栖动物多样性对关键环境因素的响应 底栖动物物种数和 Shannon-Wiener 指数与水体 TN 浓度和 栖境多样性的响应相关性显著 $(P \ll 0.001)$, 两者随着栖境多样性的升高而稳步上升 (图 4). Shannon-Wiener 指数随着水体 TN 浓度的升高呈下降趋势, 当 $\mathrm{TN}$ 浓度处于 $5 \sim 10 \mathrm{mg} / \mathrm{L}$ 时, 达到阈值浓度, 指数处于相对较 低的水平 $(<0.5)$. 类似地, 物种数随着水体 $\mathrm{TN}$ 浓度的升高急速下降; 当 $\mathrm{TN}$ 浓度大于 $5 \mathrm{mg} / \mathrm{L}$ 时, 物种数的 

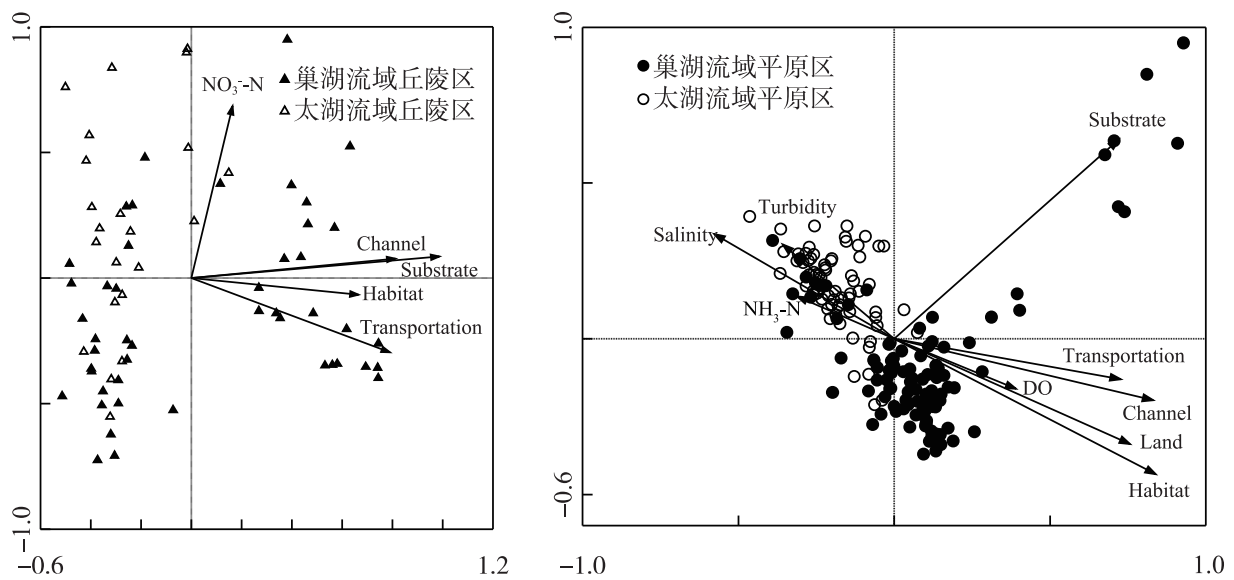

图 3 底栖动物群落结构与环境因子的典范对应分析排序图

Fig.3 Canonical correspondence analysis of macroinvertebrate community and environmental variables
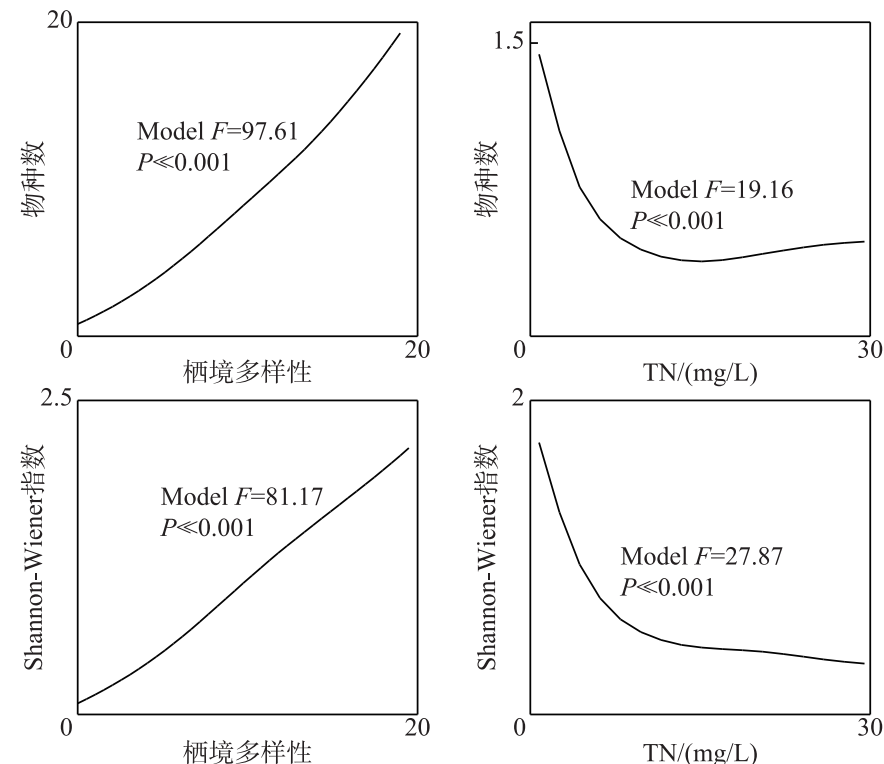

图 4 底栖动物物种数及 Shannon-Wiener 多样性指数对关键环境因素的响应曲线

Fig.4 Response curves of richness and Shannon-Wiener index to the key environmental factors

下降速度趋缓并处于较低水平.

2.4.2 底栖动物特征种对关键环境因素的响应 铜锈环棱螺和椭圆夢卜螺作为腹足纲的特征种, 对栖境多样 性、底质异质性和电导率的响应关系显著 $(P<0.05)$, 但两个特征种对上述 3 个环境因子的响应关系相差较 大(图 5). 铜锈环棱螺密度随着栖境多样性的提高呈先上升后下降的趋势, 而粗圆夢卜螺密度随着栖境多 样性的提高呈上升趋势. 铜锈环棱螺密度随着底质异质性的升高逐渐降低, 而椭圆夢卜螺对底质异质性的 响应呈单峰关系. 铜锈环棱螺对电导率的响应呈现单峰关系, 在电导率为 $0.6 \mathrm{mS} / \mathrm{cm}$ 时达到最大. 椭圆夢卜 螺密度随着电导率的升高而降低,但在电导率大于 $0.3 \mathrm{mS} / \mathrm{cm}$ 以后下降速度趋缓.

霍甫水丝蚓和苏氏尾鳃蚓作为寡毛纲的特征种, 对电导率、 $\mathrm{COD}_{\mathrm{Mn}}$ 和 TP 浓度的响应关系显著 $(P \ll$ 0.001 ), 且响应关系类似 (图 6), 其对电导率的响应均为典型的单峰关系, 均在电导率约为 $0.7 \mathrm{mS} / \mathrm{cm}$ 时达 
到峰值, 电导率继续增加时, 苏氏尾鳃蚓密度下降更快. 两特征种对 $\mathrm{COD}_{\mathrm{Mn}}$ 和 $\mathrm{TP}$ 浓度的响应关系相似, 密度 均随着指标值的增大而增大. 此外, 响应曲线的结果还显示:相同环境条件下,霍甫水丝蚓的密度远高于苏 氏尾鰓蚓。
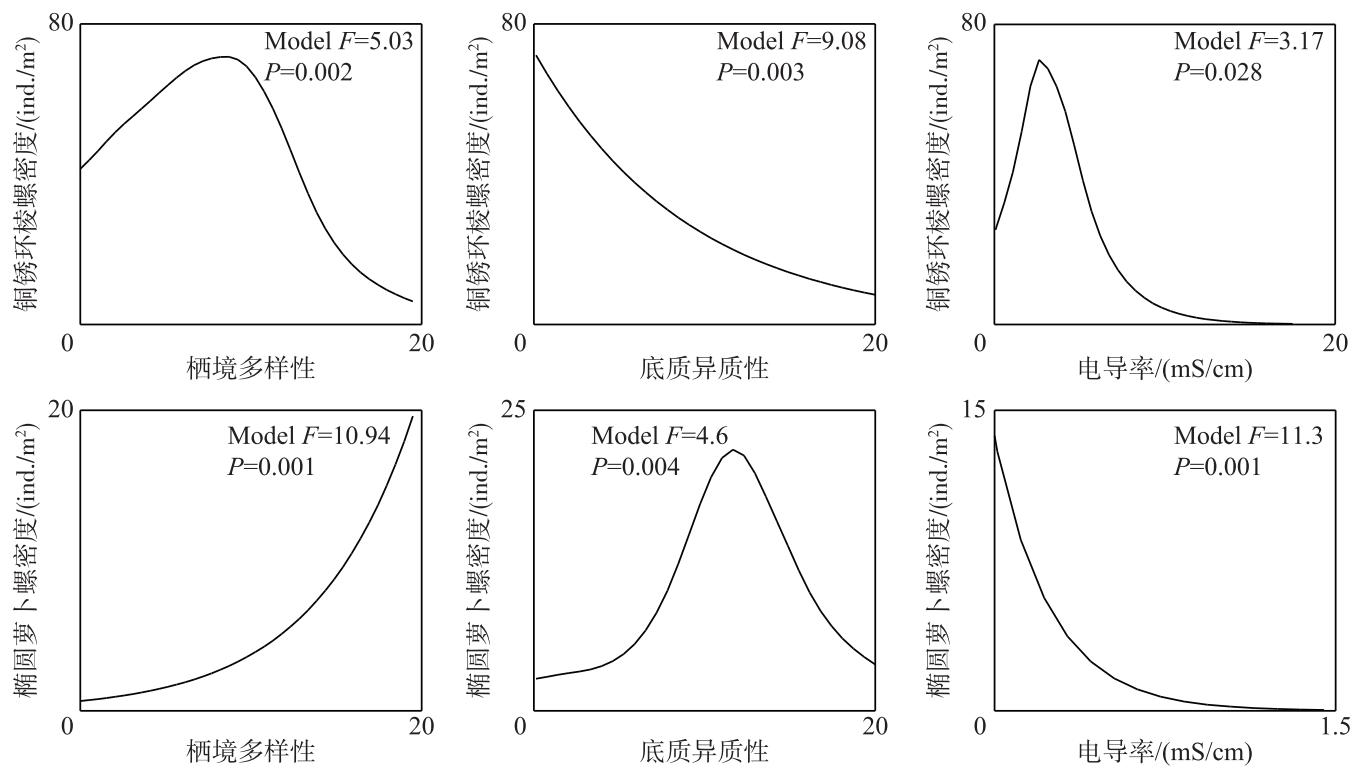

图 5 腹足纲特征种对关键环境因素的响应曲线

Fig.5 Response curves of characteristic species of Gastropod to the key environmental factors
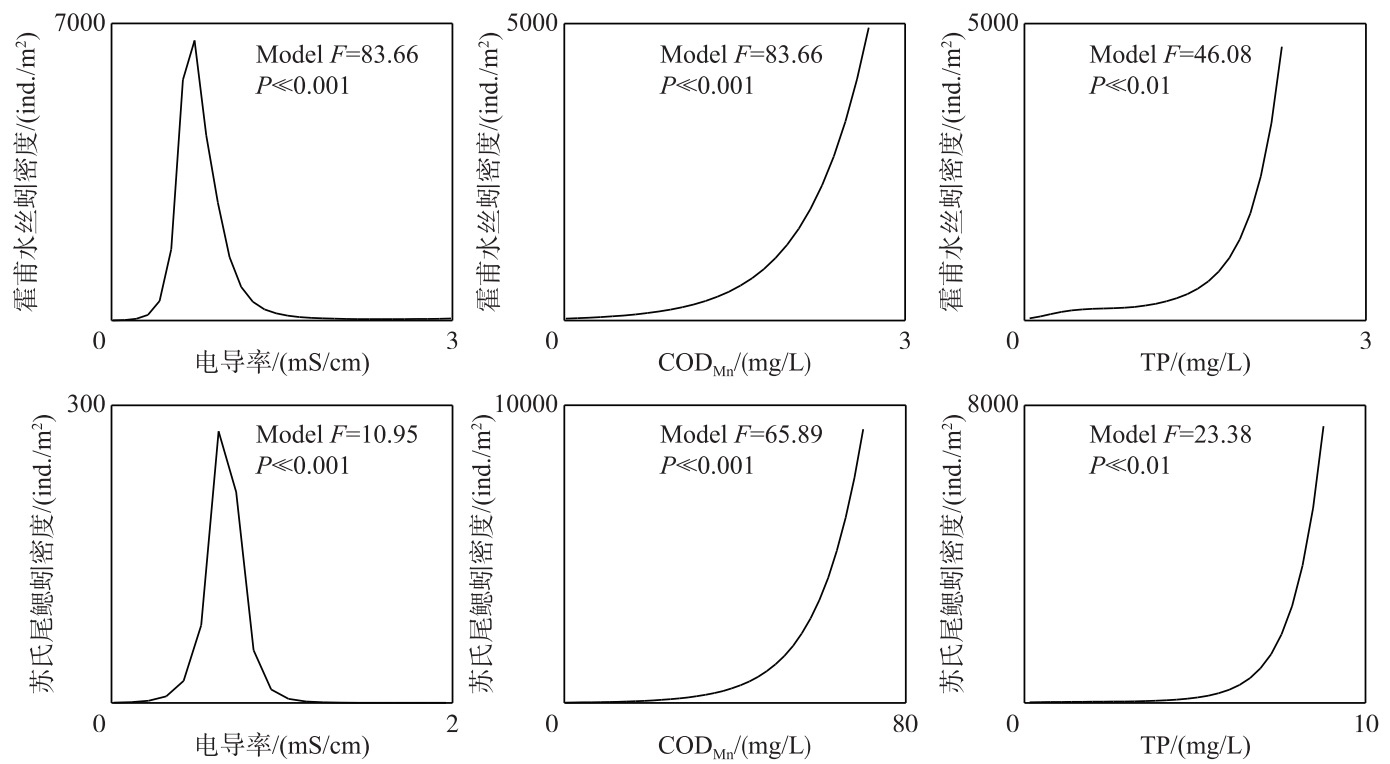

图 6 寡毛纲特征种对关键环境因素的响应曲线

Fig.6 Response curves of characteristic species of Oligochaeta to the key environmental factors

双壳纲特征种河蚬对底质异质性 $(P<0.01)$ 和 TN 浓度 $(P<0.05)$ 的响应关系显著 (图 7$)$. 河蚬对底质异 质性的响应大致呈单峰关系, 在底质异质性约为 8 时达到峰值. 河蚬密度随着 $\mathrm{TN}$ 浓度的升高而急速降低, 
但当 $\mathrm{TN}$ 浓度大于 $3 \mathrm{mg} / \mathrm{L}$ 时, 其下降速度趋缓.
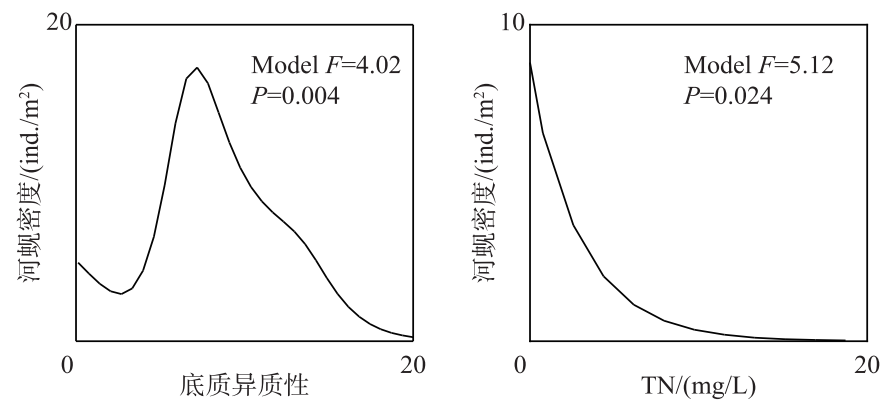

图 7 双壳纲特征种河蚬对关键环境因素的响应曲线

Fig.7 Response curves of Corbicula fluminea (Bivalvia) to the key environmental factors

摇蚊幼虫特征种黄色羽摇蚊对栖境多样性、 $\mathrm{COD}_{\mathrm{Mn}}$ 和 $\mathrm{TN}$ 的响应关系显著 $(P<0.001)$ (图 8). 黄色羽摇 蚊的密度会随着 $\mathrm{COD}_{\mathrm{Mn}}$ 的升高而增加, 而对栖境多样性和 $\mathrm{TN}$ 浓度的响应均为典型的单峰关系, 在栖境多样 性约为 6 或 TN 浓度约为 $42 \mathrm{mg} / \mathrm{L}$ 时达到峰值.

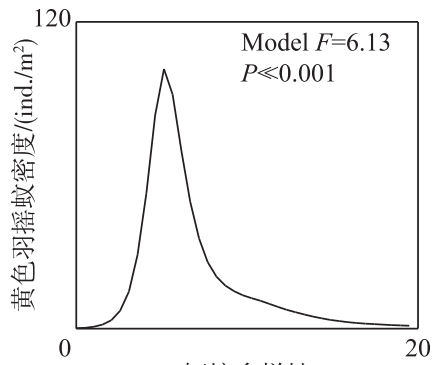

栖境多样性

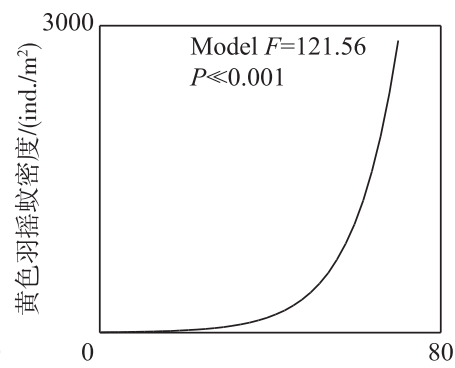

$\mathrm{COD}_{\mathrm{Mn}} /(\mathrm{mg} / \mathrm{L})$

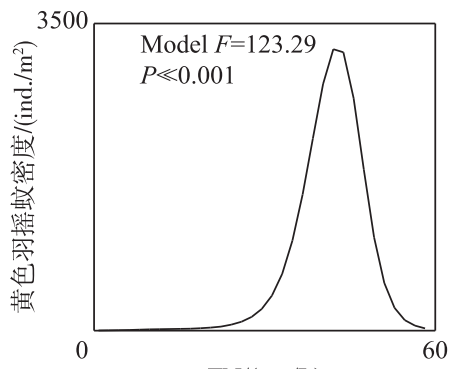

$\mathrm{TN} /(\mathrm{mg} / \mathrm{L})$

图 8 摇蚊幼虫特征种黄色羽摇蚊对关键环境因素的响应曲线

Fig.8 Response curves of Chironomus flaviplumus (Chironomidae) to the key environmental factors

研究区的两个水生昆虫类特征种对不同的环境因素响应关系较高: 扁蜉属对 $\mathrm{DO}(P \ll 0.001)$ 和 $\mathrm{COD}_{\mathrm{Mn}}$ $(P \ll 0.001)$ 的响应关系显著, 而四节蜉属对电导率 $(P \ll 0.001)$ 和 $\mathrm{TN}(P<0.05)$ 的响应关系明显 (图 9). 扁 蜉属在 DO 浓度低于 $6 \mathrm{mg} / \mathrm{L}$ 的环境中基本无法生存; 在 DO 浓度高于 $6 \mathrm{mg} / \mathrm{L}$ 的情况下, 扁蜉属密度随着 DO 的升高而上升. 扁蜉属密度随着 $\mathrm{COD}_{\mathrm{Mn}}$ 的升高而下降, $\mathrm{COD}_{\mathrm{Mn}}$ 超过 $2.1 \mathrm{mg} / \mathrm{L}$ 时, 其下降速度趋缓, 而当 $\mathrm{COD}_{\mathrm{Mn}}$ 大于 $4.2 \mathrm{mg} / \mathrm{L}$ 时, 扁蜉属几乎不出现. 四节蜉属密度随着电导率和 TN 浓度的升高而下降: 在电导率 大于 $0.3 \mathrm{mS} / \mathrm{cm}$ 的情况下, 四节蜉属的密度趋于 0 ; 在 $\mathrm{TN}$ 浓度大于 $6 \mathrm{mg} / \mathrm{L}$ 的环境中, 四节蜉属已经很难 生存.

\section{3 讨论}

\section{1 底栖动物群落结构特征差异分析}

巢湖流域大型底栖动物群落结构与太湖流域差异较大, 巢湖流域丘陵区生境质量 (栖境多样性、河道变 化、交通干扰程度和底质异质性) 优于太湖流域丘陵区. 与人类干扰强度更大的太湖流域相比, 巢湖流域大 型底栖动物的物种丰富度更高, 各采样点底栖动物的密度、物种数及多样性指数也更高. 巢湖流域是一个农 业主导型的湖泊型流域, 其河道以自然土质护坡为主. 而太湖流域的很多河流为硬质护坡, 流域内河流渠道 化程度较高, 生境退化严重, 这进一步证明了城市化和河道渠道化会严重影响大型底栖动物的结构特征 ${ }^{[4]}$. 巢湖流域大型底栖动物的物种丰富度水平和生物多样性水平与土地利用同样以农业为主的辽河流域 ${ }^{[35-36]}$ 

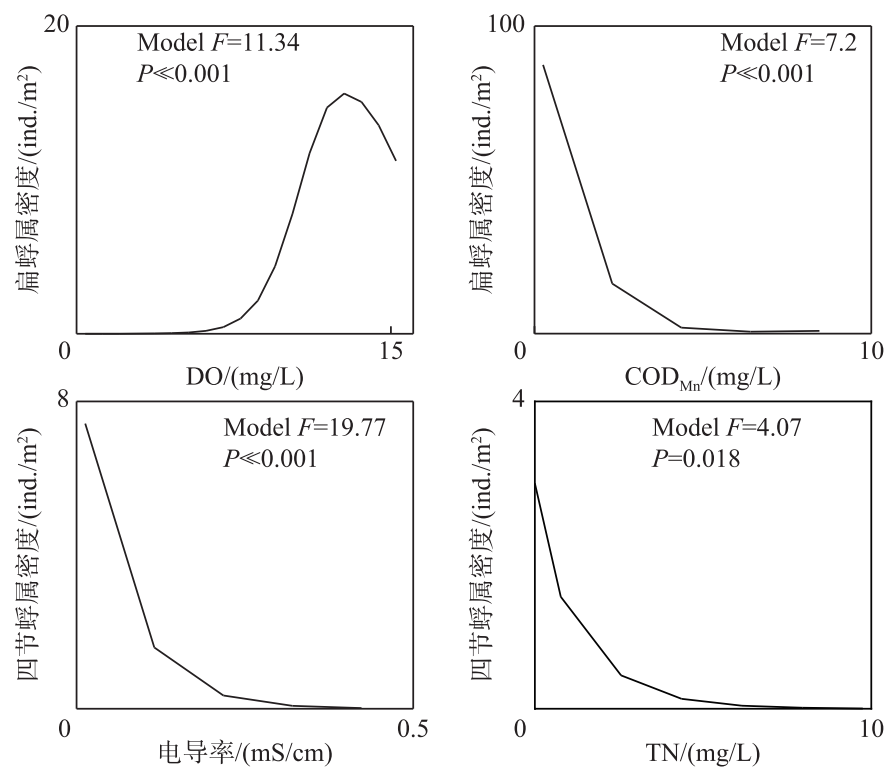

图 9 水生昆虫特征种对关键环境因素的响应曲线

Fig.9 Response curves of characteristic species of aquatic insects to the key environmental factors

相似, 但辽河流域源头溪流中的清洁种, 特别是四节蜉属昆虫 (Baetis sp.) 的数量较多, 而在第 4 级河流的点 位中摇蚊幼虫、软甲纲等耐污性物种更占优势 ${ }^{[35]}$. 此外, 辽河流域以水生昆虫为主的清洁种主要分布在以 林地为主的区域中, 在以耕地和居民住宅为主的区域摇蚊幼虫占据优势, 而以城市为主的区域寡毛纲的优 势地位明显 ${ }^{[36]}$, 说明人类活动干扰程度和土地利用类型对底栖动物群落结构空间分异影响最显著.

我国不同管理部门根据其管理需求采用的分区方式不同,如水功能区、生态功能区和主体功能区等,这 些分区方式与流域水生态功能区的分区目的、分区体系、分区方法等均不相同 ${ }^{[13]}$. 水生态功能分区主要是 面向水生态系统, 以小流域为基本单元, 考虑水生态系统的完整性和生物区系, 揭示不同区域水生生物空间 分布格局, 而水功能区则注重水体使用功能的划分, 难以反映水生态特征及水生态功能的差异. 生态功能区 是以陆地生态系统为基础的,也不适用水生态系统的管理需求. 本研究中发现,两流域的丘陵区和平原区的 特征种组成也有很大差异. 丘陵区排在前 5 位的特征种为铜锈环棱螺、扁蜉属、锯齿新米虾、椭圆夢卜螺和 膀脱螺属, 均为耐污和清洁的种类, 而平原区排在前 5 位的特征种为霍甫水丝蚓、铜锈环棱螺、苏氏尾鳃蚓、 大沼螺和黄色羽摇蚊, 均为耐污和中等耐污的种类, 说明水生态功能分区可以很好地区分底栖动物群落 特征.

\section{2 底栖动物一环境压力响应曲线的应用}

水质指标是水环境质量评价的最常用方法, 但只能代表采集时的水质状况, 并不能反映人类活动对水 环境的长期效应 ${ }^{[37]}$. 此外, 人为干扰不仅仅体现在水质状况上, 生境质量下降也是人类活动压力的重要体 现, 在研究水生生物群落响应时也应予以充分考虑. 底栖动物群落特征对水质状况及生境质量的响应具有 时间累积效应, 其监测可以真实地反映过去一段时间内的环境状况变化. 因此, 建立底栖动物群落结构特征 与环境梯度响应关系,对环境监测和淡水生物多样性保护均具有积极作用.

本研究基于 GAM 篮选并拟合了大型底栖动物对关键环境梯度的响应曲线, 结果表明底栖动物物种丰 富度、生物多样性及特征种与不同的环境因子具有显著响应关系. 栖境多样性和 TN 浓度可以作为底栖动物 生物多样性和物种丰富度的指示因子. 铜锈环棱螺和椭圆夢卜螺对电导率、底质和栖境多样性较为敏感, 但 两者的响应关系曲线不同. 这主要是因为两者生活习性不同, 粗圆夢卜螺属肺螺亚纲, 适合有水生植物分布 的水域; 而铜锈环棱螺属前鰓亚纲, 有庵和鰓, 以底栖着生藻和有机碎屑等为食, 适应性较强, 生态位较 
宽 ${ }^{[38]}$. 研究还表明, 河蚬对底质异质性的响应关系呈单峰曲线, 在底质异质性为 8 左右达到最大, 说明河蚬 偏好的沙泥混合底质; 河蚬的密度随着 TN 浓度的升高而极速降低,这可能是因为该物种对环境变化较敏 感, 可以作为水质清洁的指示物种. 霍甫水丝蚓和苏氏尾鳃蚓可以在 TP 浓度较高且 DO 浓度极低的严重污 染环境中生存. 黄色羽摇蚊可以在低 DO 的严重污染水体大量富集, 但在 TN 浓度大到一定程度时, 其密度 也会急速下降. 特别地, 霍甫水丝蚓、苏氏尾鳃蚓和黄色羽摇蚊对 $\mathrm{COD}_{\mathrm{Mn}}$ 的响应曲线均呈指数增长模式, 说 明这 3 个特征种的耐污能力极强, 可以在有机污染严重的环境中生存并大量富集 ${ }^{[39]}$. 水生昆虫的各特征种 丰度随着 $\mathrm{DO}$ 的升高而升高, 且随着 $\mathrm{COD}_{\mathrm{Mn}}$ 、TN 和电导率的升高而下降, 说明该物种类群对生境质量下降和 水质降低特别敏感, 较常出现在清洁的水体中. 这些结果都表明, 以上这些特征物种可以作为环境监测的指 示物种. 底栖动物一环境梯度的响应曲线能够更加清晰地描述底栖动物群落对环境因子的响应关系, 有利于 深人地了解水质、营养状态及生境质量与大型底栖动物群落结构的相关关系, 并进一步分析大型底栖动物 群落结构的变化趋势和演替过程.

\section{4 结论}

不同人类干扰强度河流的底栖动物群落结构差异显著, 且底栖动物物种丰富度、生物多样性和特征种 对不同环境因子的响应不同. 巢湖流域丘陵区和平原区的生境质量均优于太湖流域,但巢湖流域平原区部 分点位的水体营养盐极高于太湖流域平原区. 两个流域的大型底栖动物群落组成差异较大, 两个丘陵区的 差异物种较两个平原区更多, 丘陵区敏感型物种 (水生昆虫) 的种类更多. 巢湖流域丘陵区的水生昆虫密度 远高于太湖流域丘陵区, 太湖流域丘陵区的寡毛纲平均密度稍高于巢湖流域丘陵区,而巢湖流域平原区的 寡毛纲平均密度远高于太湖流域平原区, 这些特征与理化结果是一致的. 基于广义加性模型拟合的响应曲 线表明, 大型底栖动物物种丰富度和生物多样性对栖境多样性和 TN 浓度的响应关系显著, 不同物种类群对 不同的环境因子响应关系显著. 霍甫水丝蚓、苏氏尾鳃蚓、黄色羽摇蚊可作为水质重污染的指示种, 柱圆夢 卜螺可作为水质中污染的指示种, 而河蚬和扁蜉属、四节蜉属等水生昆虫可作为水质清洁的指示种, 可为生 物监测提供参考.

\section{5 参考文献}

[ 1 ] Covich AP, Austen MC, BÄRlocher F et al. The role of biodiversity in the functioning of freshwater and marine benthic ecosystems. BioScience, 2004, 54(8) : 767-775. DOI: 10.1641/0006-3568(2004)054[0767:TROBIT] 2.0.CO;2.

[ 2 ] Vanni MJ. Nutrient cycling by animals in freshwater ecosystems. Annual Review of Ecology and Systematics, 2002, 33(1): 341-370. DOI: 10.1146/annurev.ecolsys.33.010802.150519.

[ 3 ] Dai JC, Ni JR. Roles of benthos in the aquatic ecosystem health assessment. Ecology and Environment, 2008, 17( 5): 2107-2111. [戴纪翠, 倪晋仁. 底栖动物在水生生态系统健康评价中的作用分析. 生态环境学报, 2008, 17(5): 2107-2111.]

[ 4 ] Zhang Y, Liu L, Cheng L et al. Macroinvertebrate assemblages in streams and rivers of a highly developed region (Lake Taihu Basin, China). Aquatic Biology, 2014, 23(1) : 15-28. DOI: 10.3354/ab00600.

[ 5 ] Wang WL, Yan ZG, He L et al. Sensitivity evaluation of five zoobenthos to priority pollutants. China Environmental Science, 2013, 33(10): 1856-1862. [王伟莉, 问振广, 何丽等. 五种底栖动物对优控污染物的敏感性评价. 中国环境 科学, $2013, \mathbf{3 3}(10): 1856-1862$.]

[ 6 ] Xiong JL, Mei XG, Hu CL. Comparative study on the community structure and biodiversity of zoobenthos in lakes of different pollution states. J Lake Sci, 2003, 15(2): 160-168. DOI: 10.18307/2003.0210. [熊金林, 梅兴国, 胡传林. 不同 污染程度湖泊底栖动物群落结构及多样性比较. 湖泊科学, 2003, 15(2): 160-168.]

[ 7 ] Yang W, Li XX, Sun T et al. Macrobenthos functional groups as indicators of ecological restoration in the northern part of China's Yellow River Delta Wetlands. Ecological Indicators, 2017, 82 : 381-391. DOI : 10.1016/j.ecolind.2017.06.057.

[8] Fierro P, Arismendi I, Hughes RM et al. A benthic macroinvertebrate multimetric index for Chilean Mediterranean streams. Ecological Indicators, 2018, 91: 13-23. DOI: 10.1016/j.ecolind.2018.03.074.

[ 9 ] Crowly JM. Biogeography. The Canadian Geographer, 1967, 11(4) : 312-326. DOI: 10.1111/j.1541-0064.1967.tb00474.x.

[10] Gao JF, Gao YN eds. Delineation of aquatic ecoregions in Taihu Lake Basin. Beijing: China Environmental Science Press, 
2010. [ 高俊峰, 高永年. 太湖流域水生态功能分区. 北京: 中国环境科学出版社, 2010.]

[11] Abell R, Thieme ML, Revenga C et al. Freshwater ecoregions of the world: A new map of biogeographic units for freshwater biodiversity conservation. BioScience, 2008, 58(5) : 403-414. DOI: 10.1641/B580507.

[12] Gao JF, Gao YN, Zhang ZM. Theory and application of aquatic ecoregion delineation in lake-basin. Progress in Geography, 2019, 38(8) : 1159-1170. DOI: 10.18306/dlkxjz.2019.08.005. [高俊峰, 高永年, 张志明. 湖泊型流域水生态功能 分区的理论与应用. 地理科学进展, 2019, 38(8): 1159-1170.]

[13] Meng W, Zhang Y, Zhang N et al. Concept, characteristics, and implementary policy of freshwater ecosystem function management regionalization. Research of Environmental Sciences, 2013, 26(5): 465-471. [孟伟, 张远, 张楠等. 流域水 生态功能区概念、特点与实施策略. 环境科学研究, 2013, 26(5) : 465-471.]

[14] Meng W, Zhang Y, Zhang N et al. Study on aquatic ecological function regionalization and water quality target management in the river basin. Acta Scientiae Circumstantiae, 2011, 31(7): 1345-1351. [孟伟, 张远, 张楠等. 流域水生态功能分 区与质量目标管理技术研究的若干问题. 环境科学学报, 2011, 31(7): 1345-1351.]

[15] Sandin L, Johnson RK. Ecoregions and benthic macroinvertebrate assemblages of Swedish streams. Journal of the North American Benthological Society, 2000, 19(3) : 462-474. DOI: 10.2307/1468107.

[16] Kong WJ, Meng W, Zhang Y et al. A freshwater ecoregion delineation approach based on freshwater macroinvertebrate community features and spatial environmental data in Taizi River Basin, northeastern China. Ecological Research, 2013, 28 (4) : 581-592. DOI: $10.1007 / \mathrm{s} 11284-013-1048-7$.

[17] Hering D, Borja A, Carstensen J et al. The European Water Framework Directive at the age of 10: A critical review of the achievements with recommendations for the future. Science of the Total Environment, 2010, 408(19) : 4007-4019. DOI: 10.1016/j.scitotenv.2010.05.031.

[18] Meng YF, Li C, Zhang J et al. Community structure of macroinvertebrates and its relationship with environmental factors in different freshwater ecosystem function regions of Huntai River, China. Journal of Dalian Fisheries University, 2018, 33 (1) : 77-85. [孟云飞, 李晨, 张吉等. 浑太河春季不同水生态功能区大型底栖动物群落结构及其与环境因子的关 系. 大连海洋大学学报, 2018, 33(1): 77-85.]

[19] Zhang Y, Liu L, Cai YJ et al. Benthic macroinvertebrate community structure in rivers and streams of Lake Taihu Basin and environmental determinants. China Environmental Science, 2015, 35(5): 1535-1546. [张又, 刘凌, 蔡永久等. 太 湖流域河流及溪流大型底栖动物群落结构及影响因素. 中国环境科学, 2015, 35(5) : 1535-1546.]

[20] Gao YN, Gao JF. Delineation of aquatic ecoregions in TaihuLake Basin. Geographical Research, 2010, 29(1): 111-117. DOI: 10.11821/yj2010010011. [高永年, 高俊峰. 太湖流域水生态功能分区. 地理研究, 2010, 29(1): 111-117.]

[21] Gao JF, Zhang ZM, Huang Q eds. Aquatic eco-function regions of Chaohu Basin. Beijing: Science Press, 2017. [ 高俊 峰, 张志明, 黄琪. 巢湖流域水生态功能分区研究. 北京: 科学出版社, 2017.]

[22] Wu ZS, Wang XL, Chen YW et al. Assessing river water quality using water quality index in Lake Taihu Basin, China. Science of the Total Environment, 2018, 612: 914-922. DOI: 10.1016/j.scitotenv.2017.08.293.

[23] Zhang ZM, Gao JF, Fan XY et al. Assessing the variable ecosystem services relationships in polders over time: A case study in the eastern Chaohu Lake Basin, China. Environmental Earth Sciences, 2016, 75 (10) : 1-13. DOI: 10.1007/ s12665-016-5683-5.

[24] Liu YY, Zhang WZ, Wang YX et al eds. Economic fauna of China (freshwater mollusk). Beijing: Science Press, 1979. [刘月英, 张文珍, 王跃先等. 中国经济动物志-淡水软体动物. 北京: 科学出版社, 1979.]

[25] Morse JC, Yang L, Tian L eds. Aquatic insects of China useful for monitoring water quality. Nanjing: Hohai University Press, 1994.

[26] Wang HZ ed. Studies on taxonomy, distribution and ecology of microdrile oligochaetes of China, with descriptions of two new species from the vicinity of the Great Wall Station of China, Antarctica. Beijing: Higher Education Press, 2002. [王 洪铸. 中国小蚓类研究 (附中国南极长城站附近地区两新种). 北京: 高等教育出版社, 2002.]

[27] Tang HQ. Biosystematic study on the chironomid larvae in China (Diptera, Chironomidae) [Dissertation]. Tianjin: Nankai University, 2006. [唐红渠. 中国摇蚊科幼虫生物系统学研究 [学位论文]. 天津: 南开大学, 2006.]

[28] Editorial Board of “Monitoring and analysis methods of water and wastewater”, Ministry of Environmental Protection of the People's Republic of China ed. Monitoring and analysis methods of water and wastewater: fourth edition. Beijing: China Environmental Science Press, 2002. [ 国家环境保护总局《水和废水监测分析方法》编委会. 水和废水监测分析方 法: 第 4 版. 北京: 中国环境科学出版社, 2002.] 
[29] Barbour MT, Gerritsen J, Snyder B et al. Rapid bioassessment protocols for use in streams and wadeable rivers. Periphyton, benthic macroinvertebrates, and fish. U.S. Environmental Protection Agency, Office of Water, Washington, DC, USA, 1999.

[30] Zheng BH, Zhang Y, Li YB. Study of indicators and methods for river habitat assessment of Liao River Basin. Acta Scientiae Circumstantiae, 2007, 27(6): 928-936. [郑丙辉, 张远, 李英博. 辽河流域河流栖息地评价指标与评价方法研 究. 环境科学学报, 2007, 27(6): 928-936.]

[31] Zhou H, Zhang ZN. Rationale of the multivariate statistical software PRIMER and its application in benthic community ecology. Journal of Ocean University of Qingdao, 2003, 33(1) : 58-64. [ 周红, 张志南. 大型多元统计软件 PRIMER 的 方法原理及其在底栖群落生态学中的应用. 青岛海洋大学学报: 自然科学版, 2003, 33(1) : 58-64.]

[32] Zhang JT ed. Numerical ecology. Beijing: Science Press, 2004. [张金屯. 数量生态学. 北京: 科学出版社, 2004.]

[33] Jia B, Wang T, Wang LN et al. Concurvity in generalized additive models in study of air pollution. Journal of the Fourth Military Medical University, 2005, (3) : 280-283. [贾涁, 王粀, 王琳娜等. 广义可加模型共曲线性及其在空气污染 问题研究中的应用. 第四军医大学学报, 2005, (3) : 280-283.]

[34] Li ZG. Distribution of main species of stow net in the South Yellow Sea based on GAM and preliminary study of characteristics of ichthyoplankton assemblages in Haizhou Bay [Dissertation]. Qingdao: Ocean University of China, 2013. [ 李增光. 基于 GAM 模型的南黄海帆张网主要渔获物分布及海州湾鱼卵、仔稚鱼集群特征的初步研究 [学位论文]. 青岛: 中国海洋大学, 2013.]

[35] Gao X, Niu CJ, Chen YS et al. Spatial heterogeneity of stream environmental conditions and macroinvertebrates community in an agriculture dominated watershed and management implications for a large river (the Liao River, China) basin. Environmental Monitoring and Assessment, 2014, 186(4) : 2375-2391. DOI: 10.1007/s10661-013-3545-0.

[36] Li FY, Lang HW, Wang YJ et al. Impacts of land use on the spatial and temporal distribution characteristics of the macroinvertebrates in the Liao River basin. Acta Scientiae Circumstantiae, 2016, 36(3) : 767-777. DOI: 10.13671/j.hjkxxb. 2015.0624. [李法云, 郎红伟, 王艳杰等. 辽河流域典型支流土地利用方式对大型底栖动物群落时空分布特征的 影响. 环境科学学报, 2016, 36(3): 767-777.]

[37] Chen XH, Kang LJ, Sun CJ et al. Development of multi-metric index based on benthic macroinvertebrates to assess river ecosystem of a typical plain river network in China. Acta Hydrobiologica Sinica, 2013, 37(2) : 191-198. DOI: 10.7541/ 2013.4. [陈小华, 康丽娟, 孙从军等. 典型平原河网地区底栖动物生物指数篮选及评价基准研究. 水生生物学报, 2013, 37(2) : 191-198.]

[38 ] Cao ZG, Jiang XP. The influence of environmental factors on Bellamya purificate. Journal of Shanghai Fisheries University, 1998, (3) : 200-205. [曹正光, 蒋忻坡. 几种环境因子对梨形环棱螺的影响. 上海水产大学学报, 1998, (3) : 200-205.]

[39] Gong ZJ, Xie P, Tang HJ et al. The influence of eutrophication upon community structure and biodiversity of macrozoobenthos. Acta Hydrobiologica Sinica, 2001, 25(3) : 210-216. [龚志军, 谢平, 唐汇涓等. 水体富营养化对大型底栖动 物群落结构及多样性的影响. 水生生物学报, 2001, 25(3): 210-216.] 